Info Artikel

Diterima : 29 Maret 2020

Disetujui : 13 Juli 2020

Dipublikasikan : 20 Juli 2020

\title{
Pandangan Dunia Okky Madasari Tentang Pendidikan Karakter dalam Novel Pasung Jiwa dan Implikasinya Terhadap Pembelajaran Sastra di SMA
}

\author{
Achmad Sultoni $^{1 凶}$, Hari Widi Utomo ${ }^{2}$ Shintia Dwi Alika ${ }^{3}$ \\ ${ }^{123}$ Institut Teknologi Telkom Purwokerto \\ ${ }^{1}$ sultoni@ittelkom-pwt.ac.id
}

\begin{abstract}
Literature is a work of art that is full of valuable messages. The message in this valuable literary work needs to be explored through an in-depth study. This study aims to describe Okky Madasari's world view of character education in Pasung Jiwa novel. The source of research data is Pasung Jiwa novel by Okky Madasari. This research employed a descriptive qualitative research with a method of describing an in-depth data. Data is collected through the stages of reading the text of the novel carefully, classifying, interpreting, confirming, and concluding the analysis results. The results of this study indicate four character values found in Pasung Jiwa novel by Okky Madasari namely religious, friendly, peace-loving, and hard work. This novel is relevant and suitable for a teaching material for teachers in studying literature in high school because it contains the values of character education.
\end{abstract}

Keywords: character educations, literature, and structuralism genetic

Abstrak: Sastra merupakan karya seni yang sarat akan pesan adiluhung. Pesan dalam karya sastra yang adiluhung tersebut perlu digali, di antaranya melalui sebuah kajian mendalam. Penelitian ini bertujuan untuk mendeskripsikan pandangan dunia Okky Madasari tentang pendidikan karakter dalam novel Pasung Jiwa. Sumber data dalam penelitian adalah novel Pasung Jiwa karya Okky Madasari. Penelitian ini tergolong penelitian kualitatif deskriptif dengan metode mendeskripsikan data secara mendalam. Data dikumpulkan melalui tahapan pembacaan teks novel secara seksama, mengklasifikasikan data, menafsirkan hasil analisis data, mengkonfirmasi hasil analisis, dan menyimpulkan hasil analisis. Hasil dari penelitian ini menunjukkan terdapat empat nilai karakter yang terdapat dalam novel Pasung Jiwa karya Okky Madasari. Keempat nilai Pendidikan karakter tersebut yaitu: religius, bersahabat, cinta damai, dan kerja keras. Novel Pasung Jiwa karya Okky Madasari relavan untuk menjadi bahan ajar guru dalam pembelajaran sastra di SMA karena novel Pasung Jiwa mengandung nilai-nilai pendidikan karakter.

Kata Kunci: pendidikan karakter, sastra, strukturalisme genetik, okky madasari

Sitasi Artikel:

Sultoni, A., Utomo, H., \& Alika, S. (2020). Pandangan Dunia Okky Madasari Tentang Pendidikan Karakter dalam Novel Pasung Jiwa dan Implikasinya Terhadap Pembelajaran Sastra di SMA. Disastra: Jurnal Pendidikan Bahasa dan Sastra Indonesia, 2(2), 133-140. doi:http://dx.doi.org/10.29300/disastra.v2i2.2978 


\section{Pendahuluan}

Karakter merupakan aspek penting dalam peradaban masyarakat suatu bangsa. Undang-Undang Republik Indonesia Nomor 20 Tahun 2003 tentang Sistem Pendidikan Nasional (Sisdiknas) telah merumuskan fungsi dan tujuan pendidikan nasional. Pasal 3 UU Sisdiknas No. 20 Tahun 2003 tersebut dinyatakan bahwa tujuan dari pendidikan nasional, yaitu "pendidikan nasional berfungsi mengembangkan kemampuan dan membentuk watak serta peradaban bangsa yang bermartabat dalam rangka mencerdaskan kehidupan bangsa, bertujuan untuk berkembangnya potensi peserta didik agar menjadi manusia yang beriman dan bertakwa kepada Tuhan, berakhlak mulia, sehat, berilmu, cakap, mandiri, dan menjadi warga negara yang demokratis serta bertanggung jawab."

Sudewo (2011:13) menyatakan bahwa pembentukan kualitas manusia yang unggul sejatinya senantiasa memerlukan peran pendidikan karakter. Posisi karakter bukan jadi pendamping kompetensi atau kemampuan, melainkan menjadi dasar, roh, atau jiwanya. Tanpa karakter, peringkatan diri dari kompetensi dapat menjadi liar, berjalan tanpa rambu, dan aturan. Oleh karena itu, penanaman nilai pendidikan karakter harus senantiasa diajarkan agar manusia memperoleh harkat dan martabat yang tinggi, baik di hadapan manusia, maupun di hadapan Tuhan.

Karya sastra sangat erat hubungannya dengan pendidikan karakter. Apabila dihayati dengan baik, karya sastra dapat menjadi sarana penanaman nilai pendidikan karakter. Hal itu berpijak pada pandangan bahwa karya sastra selain sebagai sarana hiburan juga sebagai sarana edukasi.
Sarumpaet (2017:73) menyatakan bahwa setiap membaca karya sastra, akan ada dua hal yang diperoleh pembaca: pertama, kesenangan dan kedua, pengetahuan. Sejalan dengan pandangan Wibowo (2013:129), karya sastra dapat digunakan sebagai media pembentuk watak moral anak didik. Karya sastra dapat menyampaikan pesan-pesan moral baik secara implisit maupun eksplisit. Dengan mengapresiasi cerpen, novel, cerita rakyat, dan puisi, seseorang dapat membentuk karakter siswa. Nilai-nilai kejujuran, keiklasan, ketulusan, kebersamaan, religiusitas, dan sebagainya yang berhubungan dengan pendidikan karakter, bisa diinternalisasikan kepada anak didik melalui karya sastra atau sastra.

Senada dengan pendapat Sultoni (2015:232) yang menyatakan bahwa dalam konteks kebudayaan, sastra memiliki posisi penting dalam pembentukan karakter bangsa. Demikian pula dalam porsi pembentukan mental, sebab dunia dalam sastra merupakan dunia yang dibangun atas dialektika ruang keindahan dan nilai. Sastra hadir dengan fungsinya sebagai bagian untuk mendidik masyarakat.

Pendapat tersebut dapat disintesiskan bahwa karya sastra dapat menjadi media efektif dan edukatif dalam menunjang penanaman nilai-nilai pendidikan karakter. Pendidikan karakter dalam karya sastra dapat dilakukan melalui internalisasi nilainilai kebajikan dalam karya sastra yang berupa peneladanan sikap yang baik seperti kejujuran, kearifan, kebijaksanaan, cinta kasih, dan hakikat kebaikan lainnya sehingga penanaman karakter dapat dilakukan.

Bertemali dengan hal tersebut, novel Pasung Jiwa karya Okky Madasari sarat 
akan nilai pendidikan karakter yang penting untuk diteliti. Secara garis besar novel Pasung Jiwa menceritakan perihal potret kehidupan dua tokoh utama bernama Sasana dan Jaka Wani. Dalam narasi cerita digambarkan bahwa tokoh Sasana dan Jaka Wani merupakan sosok yang penuh semangat menjalani kehidupan. Situasi kehidupan yang sulit tidak membuat kedua tokoh tersebut menyerah.

Penggambaran kehidupan tokoh Sasana dan Jaka Wani dengan lingkup sosialnya tersebut penting untuk diperhatikan karena dapat menjadi media edukasi bagi masyarakat pembaca. Hal tersebut relevan dengan fungsi karya sastra, yaitu sebagai sarana hiburan dan wahana pendidikan. Demikian pula dalam konteks pendidikan di sekolah, berbagai persoalan sosial yang diangkat oleh pengarang dapat menjadi bagian dalam menanamkan pendidikan karakter.

Penelitian ini menggunakan pendekatan strukturalisme genetik. Pandangan dunia diartikan sebagai kompleks menyeluruh dari gagasangagasan, aspirasi-aspirasi, dan perasaanperasaan yang menghubungkan secara bersama-sama anggota-anggota suatu kelompok sosial tertentu dan yang mempertentangkannya dengan anggota kelompok sosial lain. Pandangan dunia bagi bukan merupakan fakta empiris yang langsung, tetapi lebih merupakan struktur gagasan, aspirasi, dan perasaan yang dapat menyatukan suatu kelompok sosial di hadapan suatu kelompok sosial lain. Jadi pandangan dunia adalah suatu abstraksi (Rosyidi dkk., 2010:202).

Pandangan dunia Goldman lebih dimaknai sebagai sebuah bentuk ide atau pemikiran pengarang tentang keadaan sosial masyarakat tertentu. Keadaan sosial masyarakat tersebut selanjutnya memicu pengarang dalam memunculkan pandangan ideal dengan media karya sastra.

Sangidu (2004:29) berpendapat bahwa dalam menerapkan pendekatan strukturalisme bergerak melalui tiga hal sebagai berikut: (a) analisis struktur karya sastra lewat unsur-unsur yang membangun teksnya dan memahaminya sebagai suatu keseluruhan strukturnya; (b) analisis struktur sosial historis konkret yang melatarbelakangi lahirnya karya sastra; (c) analisis pandangan dunia (vision du monde).

Penelitian ini mengambil aspek pandangan dunia (vision $d u$ monde) untuk mengetahui pandangan dunia pengarang Okky Madasari tentang pendidikan karakter dalam novel Pasung Jiwa. Sehandi (2014:177) mengatakan bahwa pandangan dunia dalam karya sastra yang agung adalah suatu abstraksi, bukan fakta empiris yang memiliki memiliki objektif. Pandangan dunia merupakan suatu bentuk kesadaran kolektif yang mewakili identitas kolektifnya, maka secara sahih mewakili kelas sosialnya. Pandangan dunia inilah yang dipahami mempengaruhi bahkan menentukan struktur karya sastra. Oleh karena itu, karya sastra dapat dipahami asalnya dan bagaimana terjadinya (unsur genetiknya) dari latar belakang sosialnya.

Penelitian ini bermaksud untuk mengetahui pandangan dunia Okky Madasari dalam novelnya berjudul Pasung Jiwa. Pandangan dunia tersebut dikhususkan terhadap nilai pendidikan karakter yang diketengahkan oleh pengarang dalam novel Pasung Jiwa. 


\section{Metode Penelitian}

Tujuan penelitian ini adalah untuk memperoleh dan mendeskripsikan secara mendalam nilai-nilai pendidikan karakter novel Pasung Jiwa karya Okky Madasari dengan pendekatan strukturalisme genetik. Sumber data penelitian ini adalah novel Pasung Jiwa karya Okky Madasari. Dari novel tersebut diperoleh data yang berhubungan dengan pandangan dunia pengarang perihal nilai-nilai pendidikan karakter yang menjadi fokus kajian ini. Data diperoleh melalui teknik pembacaan intensif dan pencatatan. Selanjutnya, data dianalisis dengan metode deskriptif kualitatif berdasarkan kerangka teori strukturalisme genetik.

Adapun teknik analisis data yang digunakan dalam penelitian ini adalah teknik analisis model interaktif, sehalnya yang dikemukakan oleh Miles dan Huberman (1992:20) yang terdiri atas tiga komponen analisis, yaitu reduksi data, sajian data, dan penarikan simpulan atau verifikasi. Aktivitas ketiga komponen itu dilakukan dalam bentuk interaktif dengan proses pengumpulan data.

\section{Hasil dan Pembahasan}

Nilai secara etimologi merupakan pandangan kata value (bahasa Inggris) (moral value). Dalam konteks kehidupan, nilai dapat diasumsikan sebagai sesuatu yang berharga, berguna bagi kehidupan manusia. Dalam pembahasan nilai sebagai bagian penting kehidupan, nilai dapat dimaknai sebagai kualitas yang berbasis moral (Zakiyah, 2014:14).

Sulistyowati

mendefinisikan pendidikan karakter sebagai pendidikan yang mengembangkan nilai-nilai budaya dan karakter bangsa pada diri seseorang siswa, sehingga mereka memiliki dan menerapkan nilai-nilai tersebut dalam kehidupan dirinya sebagai anggota masyarakat dan warga negara yang religius, produktif, dan kreatif.

Wibowo (2013:15-16) mengatakan bahwa berdasarkan Kemendiknas (2010), ke-18 nilai pendidikan karakter yaitu: religious, jujur, toleransi, disiplin, kerja keras, kreatif, mandiri, demokratis, rasa ingij tahu, semangat kebangsaan, cinta tanah air, menghargai prestasi orang lain, bersahabat, cinta damai, gemar membaca, peduli lingkungan, peduli sosial, dan tanggung jawab.

Penelitian ini bertujuan untuk mengetahui pandangan dunia Okky Madasari tentang nilai pendidikan karakter dalam novel Pasung Jiwa. Adapun pembahasannya adalah sebagai berikut:

\section{Karakter Religius}

Religius adalah nilai karakter dalam hubungannya dengan Tuhan. Karakter religius menunjukkan bahwa pikiran, perkataan, dan tindakan seseorang yang diupayakan selalu berdasarkan pada nilainilai ketuhanan dan ajaran agamanya (Mustari, 2014:1).

Dalam novel Pasung Jiwa terdapat nilai pendidikan karakter religius. Nilai pendidikan karakter tersebut digambarkan melalui kesadaran Cak Jek mengingat Tuhan Yang Maha Esa. Tokoh Cak Jek dalam novel Pasung Jiwa merasa digetarkan hatinya ketika mendengarkan lantunan azan. Hal tersebut terlihat pada kutipan berikut:

"Azan dari masjid sebelah terdengar. Jali mengajakku salat bersama. Aku sebenarnya mau menolak. Bertahun-tahun aku tak 
pernah salat. Bahkan bisa dibilang sejak kecil aku hanya salat ketika lebaran dan salat bersama di sekolah. Aku tak bisa salat. Aku tak pernah hafal doa yang harus dibaca saat salat. Aku juga tak tahu kenapa harus salat. Blas... aku tidak kepingin salat. Tapi kok rasanya mulutku terkunci. Aku tak sampai hati menolak ajakan Jali" (Madasari, 2015:252).

Kutipan di atas menunjukkan karakter religius yaitu kesadaran Cak Jek untuk melaksanakan salat. Diakui oleh Cak Jek bahwa sudah lama sekali oleh Cak Jek telah meninggalkan salat. Bahkan dapat dikatakan, Cak Jek melaksanakan salat hanya ketika Idulfitri. Meski dalam hatinya sesungguhnya terbesit rasa ingin mengingkari salat, namun secara tiba-tiba hatinya tergerak untuk melaksanakan salat berjamaah bersama Jali.

\section{Karakter Cinta Damai}

Cinta damai merupakan sikap, perkataan, dan tindakan yang menyebabkan orang lain merasa senang dan aman atas kehadiran dirinya (Wibowo, 2013:16). Nilai cinta damai dalam novel Pasung Jiwa ditunjukkan oleh sikap Cak Jek yang berusaha menasihati Sasana agar tidak suka berkelahi. Nilai karakter cinta damai tercermin dalam kutipan berikut:

Sejak malam itu kami tak lagi datang ke daerah alun-alun. Cak Jek masih takut orang yang kuhajar sakit hati dan bakal menyerang bahkan membunuh kami. Kami lebih banyak ngamen di daerah kampus atau pinggiran kota. Warung Cak Man menjadi markas kami tiap malam. Cak Jek mewanti-wanti agar aku tak gampang main tangan dengan orang. "Pakai mulut saja. Hajar pakai mulut!" kata Cak Jek" (Madasari, 2015:63).

Kutipan tersebut menunjukkan bahwa Cak Jek memperingatkan Sasana untuk tidak main tangan. Kejadian ketika Sasana menyerang para preman di alun-alun menjadi pengalaman berharga bagi Cak Jek. Cak Jek beranggapan bahwa melakukan tindak kekerasan pada orang lain tidak baik dilakukan. Karena itu Sasana diperingatkan Cak Jek agar main hajar dengan perkataan saja tetapi tidak menggunakan tangan.

\section{Karakter Bersahabat}

Karakter bersahabat atau komunikatif memiliki pengertian tindakan yang memperlihatkan rasa senang berbicara, bergaul dan bekerja sama dengan orang lain (Wibowo, 2013:15-16). Pendapat tersebut mengasumsikan bahwa seseorang dikatakan memiliki karakter bersahabat atau komunikatif apabila dalam diri seseorang tersebut tertanam sikap senang berinteraksi atau bergaul dengan orang lain.

"Mereka meninggalkan kami setelah
mengucapkan salam. Sangat sopan.
Lain sekali dengan penampilannya
yang sangar dan bau badannya yang
super-penguk" (Madasari, 2015:68-
$69)$.

Kutipan tersebut menggambarkan adanya karakter bersahabat berupa sikap santun terhadap orang lain. Sikap santun tersebut ditunjukkan oleh tokoh anak-anak marjinal dengan mengucapkan salam ketika bertemu orang lain. Anak-anak marjinal yang dikenal sebagai pribadi yang berpenampilan sangar dan pakaian yang 
compang-camping justru memiliki sikap yang santun.

\section{Karakter Kerja Keras}

Kerja keras merupakan perilaku yang menunjukkan upaya sungguh-sungguh dalam menghadapi berbagai hambatan belajar dan tugas serta menyelesaikan tugas dengan sebaik-baiknya (Wibowo, 2013:1516). Kerja keras disertai sikap pantang menyerah agar tugas dan hal yang dicitacitakan dapat tercapai.

"Kita harus optimis. Kita bisa jadi bintang! Ya, memang bukan seperti bintang di TV itu. Tapi yang penting kita harus profesional," kata Cak Jek" (Madasari, 2015:51).

"Nah, itu dia. Selamanya nasib kita akan seperti ini. Kerja, makan, kerja, makan," kata orang itu lagi. "Masa kita mau seperti ini terus? Kita harus melakukan perubahan," lanjutnya" (Madasari, 2015:66).

Seruan pantang menyerah dan bekerja dengan total dilakukan oleh tokoh Cak Jek dan anak-anak marginal Kedua petuah tersebut diberikan agar sebagai generasi muda jangan mudah menyerah. Cara yang paling baik agar harapan dapat tercapai salah satunya adalah dengan bertindak dan mengerjakan penuh totalitas. Demikian semangat pantang menyerah ditunjukkan dalam novel Pasung Jiwa.

\section{Implikasi Novel Pasung Jiwa karya Okky Madasari terdahap Pembelajaran Sastra di SMA}

Pembelajaran sastra pada hakikatnya adalah menumbuhkan sikap apresiatif siswa untuk menghargai karya sastra. Harapan tersebut nantinya dapat mengantarkan siswa mau memahami dan menghayati pesan dan nilai yang ditawarkan karya sastra. Hal tersebut menjadi penting sebagai usaha membentuk generasi bangsa yang berwatak unggul dan berkarakter.

Upaya untuk mencapai tujuan dalam pembelajaran apresiasi sastra, guru semestinya berfungsi sebagai mediator dan fasilitator harus mampu mengupas unsurunsur yang membangun karya sastra secara utuh dan terpadu. Artinya, guru dapat memadukan antara unsur intrinsik dan unsur ekstrinsik dalam pembelajaran apresiasi sastra, sehingga tujuan yang diharapkan dapat tercapai secara optimal (Randi, 2019:66).

Sementara itu, Hardiningtyas (2008:103) menyatakan bahwa pembelajaran sastra bertujuan untuk menanamkan nilai-nilai moral, etika, budi pekerti, dan kemanusiaan pada peserta didik. Nilai moral tersebut nantinya akan menjadi pedoman bagi siswa dalam menjalankan kehidupan yang nyata di masyarakat.

Hal ini sejalan dengan amanat Undang-Undang Dasar No. 20 Tahun 2003 Pasal 3 yang menyebutkan bahwa pendidikan nasional berfungsi "mengembangkan kemampuan dan membentuk watak serta peradaban bangsa yang bermartabat dalam rangka mencerdaskan kehidupan bangsa, bertujuan untuk berkembangnya potensi peserta didik agar menjadi manusia yang beriman dan bertakwa kepada Tuhan Yang Maha Esa, berakhlak mulia, sehat, berilmu, cakap, kreatif, mandiri, dan menjadi warga negara yang demokratis serta bertanggung jawab".

Kurikulum yang dilaksanakan pada saat ini mengacu pada kurikulum baru yaitu Kurikulum 2013 (K-13). Di mana 138 
pembelajaran sastra di Sekolah Menengah Atas (SMA) berfokus mengenai struktur yang ada pada karya sastra terutama novel. Dalam Kurikulum 2013 pembelajaran ditekankan pada aspek efektif atau perubahan perilaku dan kompetensi yang ingin dicapai adalah kompetensi yang berimbang antara sikap, keterampilan dan pengetahuan.

Pembelajaran novel yang dikemukakan dalam landasan teori di atas adalah pembelajaran novel untuk Sekolah Menengah Atas (SMA). Di mana Kurikulum 2013 diberlakukan berdasarkan Peraturan Menteri Pendidikan Nasional Nomor 64 Tahun 2013 tentang standar isi untuk pendidikan dasar dan menengah. Dalam Kurikulum 2013 pembelajaran novel berlangsung pada jenjang kelas XII semester dua. Dengan demikian, telaah pembelajaran novel dalam konteks penelitian ini difokuskan pada pembelajaran novel di kelas XII.

Berdasarkan silabus yang ada menunjukkan bahwa kompetensi dasar dalam pembelajaran novel tersebut yaitu: (1) memahami struktur dan kaidah teks fiksi dalam novel baik melalui lisan maupun tulisan, (2) menganalisis teks cerita fiksi dalam novel baik melalui lisan maupun tulisan, dan (3) menginterpretasikan makna teks cerita fiksi dalam novel baik secara lisan maupun tulisan. Sementara indikator pembelajaran meliputi: (1) kemampuan memahami struktur teks cerita fiksi dalam novel, (2) kemampuan memahami ciri kebahasaan dalam teks cerita fiksi dalam novel, (3) kemampuan menggunakan dan menyampaikan hasil pemahaman terhadap struktur dan ciri kebahasaan teks cerita fiksi dalam novel, dan (4) kemampuan memahami isi teks cerita fiksi dalam novel.
Kompetensi dasar dan materi pembelajaran novel di SMA dapat dicermati dari tebel berikut.

Tabel 1. Silabus tentang Pembelajaran Novel

\begin{tabular}{|c|c|}
\hline Kompetensi Dasar & Materi \\
\hline $\begin{array}{l}3.1 \text { Memahami struktur } \\
\text { dan kaidah teks cerita fiksi } \\
\text { dalam novel baik melalui } \\
\text { lisan maupun tulisan. }\end{array}$ & $\begin{array}{l}\text { Struktur teks cerita } \\
\text { ifiksi dalam novel. } \\
\text { i }\end{array}$ \\
\hline $\begin{array}{l}3.2 \text { Menganalisis teks } \\
\text { cerita fiksi dalam novel } \\
\text { baik melalui lisan maupun } \\
\text { tulisan. }\end{array}$ & \begin{tabular}{ll} 
Ciri & \multicolumn{2}{c}{ kebahasaan } \\
teks & cerita fiksi \\
dalam novel.
\end{tabular} \\
\hline $\begin{array}{l}3.2 \text { Menginterpretasi } \\
\text { makna teks cerita fiksi } \\
\text { dalam novel baik secara } \\
\text { lisan maupun tulisan. }\end{array}$ & $\begin{array}{l}\text { Memahami isi dan } \\
\text { makna teks cerita } \\
\text { fiksi dalam novel. }\end{array}$ \\
\hline
\end{tabular}

Berpijak pada hal yang tersebut di atas novel Pasung Jiwa karya Okky Madasari dipandang sesuai untuk digunakan sebagai materi pembelajaran sastra khususnya dalam pembelajaran novel. Hal ini dikarenakan novel Pasung Jiwa mengandung nilai-nilai pendidikan karakter. Nilai-nilai pendidikan karakter yang terdapat dalam novel Pasung Jiwa yaitu: religius, cinta damai, kerja keras, dan bersahabat sebagai hasil pemaknaan terhadap karya sastra.

\section{Simpulan}

Penelitian ini bertujuan untuk mendeskripsikan pandangan dunia Okky Madasari tentang pendidikan karakter dalam novelnya yang berjudul Pasung Jiwa. Adapun pandangan dunia Okky Madasari tentang pendidikan karakter meliputi: religius, cinta damai, bersahabat, dan kerja keras. Novel Pasung Jiwa karya Okky Madasari relavan untuk menjadi bahan ajar 
guru dalam pembelajaran sastra di SMA. Hal ini dikarenakan novel Pasung Jiwa mengandung nilai-nilai pendidikan karakter. Nilai-nilai karakter tersebut digali oleh siswa melalui pembelajaran menelaah karya sastra novel di kelas XII semester 2 .

\section{Daftar Pustaka}

Faruk. (2014). Metode Penelitian Sastra. Yogyakarta: Pustaka Pelajar.

Hardinigtyas, Puji Retno. (2008). Implementasi Pengajaran Sastra Indonesia di Sekolah: Upaya Pemahaman Pembelajaran Berbasis Kompetensi dan Pendekatan Kontekstual. Jurnal Aksara. Denpasar: Slamat Trisila.

Madasari, Okky. (2015). Pasung Jiwa. Jakarta: Gramedia Pustaka Utama.

Mustari, M. (2014). Nilai Karakter Refleksi untuk Pendidikan. Jakarta: Rajagrafindo Persada.

Randi. (2019). Aspek Religius dan Moral Novel 99 Cahaya Di Langit Eropa Karya Hanum Salsabiela Rais dalam Pembelajaran Apresiasi Sastra di Sekolah Menengah Atas. Disastra, 1 (1), 65-70.

Rokhmansyah, A. 2014. Studi dan Pengkajian Sastra Perkenalan Awal terhadap Ilmu Sastra. Yogyakarta: Graha Ilmu.

Rosyidi, dkk. (2010). Analisis Teks Sastra: Mengungkap Makna, Estetika, dan Ideologi dalam Perspektif Teori Formula, Semiotik, Hermenutik, dan Struktutalisme Genetik .Yogyakarta: Graha Ilmu.
Sangidu. 2004. Penelitian Sastra: Pendekatan, Teori, Metode dan Kiat. Yogyakarta: UGM.

Sarumpaet, Riris K. Toha. 2017. Pedoman Penelitian Sastra Anak: Jakarta: YOI.

Sulistyowati, E. 2012. Implementasi Kurikulum Pendidikan Karakter. Yogyakarta: Citra Adi Parama.

Sudewo, E. 2011. Character Building. Jakarta: Republika.

Sultoni, Achmad dan Hubbi Saufan Hilmi. (2015). Pembelajaran Sastra Berbasis Kearifan Lokal Sebagai Upaya Optimalisasi Pendidikan Karakter Kebangsaan Menuju Masyarakat Ekonomi ASEAN (MEA). Prosiding. Seminar Nasional Pendidikan Bahasa Indonesia. Universitas Muhammadiyah Surakarta, 229-236.

Undang-Undang Republik Indonesia Nomor 20 Tahun 2003 tentang Sistem Pendidikan Nasional (Sisdiknas). Diunduh dari http://hukum.unsrat.ac.id/uu/uu_20_03. $\underline{\mathrm{htm}}$.

Wibowo, A. 2013. Pendidikan Karakter Berbasis Sastra. Yogyakarta: Pustaka Belajar.

Zakiyah, Y. Q. dan A. Rudiana. 2014. Pendidikan Nilai Kajian Teori dan Praktik di Sekolah. Bandung: Pustaka Setia. 